WellBeing International

WBI Studies Repository

7-2005

\title{
Differential Stress Responses in Fish from Areas of High- and Low-Predation Pressure
}

Culum Brown

University of Edinburgh

Carolyn Gardner

University of Edinburgh

Victoria Braithwaite

University of Edinburgh

Follow this and additional works at: https://www.wellbeingintlstudiesrepository.org/acwp_aff

Part of the Animal Studies Commons, Other Animal Sciences Commons, and the Veterinary

Physiology Commons

\section{Recommended Citation}

Brown, C., Gardner, C., \& Braithwaite, V. A. (2005). Differential stress responses in fish from areas of highand low-predation pressure. Journal of Comparative Physiology B, 175(5), 305-312.

This material is brought to you for free and open access by WellBeing International. It has been accepted for inclusion by an authorized administrator of the WBI Studies Repository. For more information, please contact wbisr-info@wellbeingintl.org.

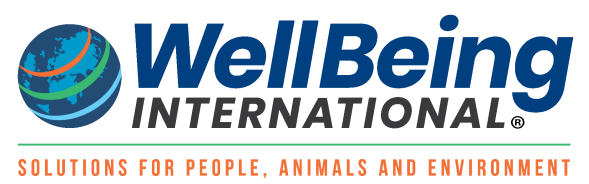




\title{
Differential Stress Responses in Fish from Areas of High- and Low-Predation Pressure
}

\author{
Culum Brown, Carolyn Gardner, Victoria A. Braithwaite \\ University of Edinburgh
}

\author{
KEYWORDS \\ Predators, prey, stress responses, evolution, Brachyraphis episcopi
}

\begin{abstract}
We subjected fish from regions of high and low levels of predation pressure in four independent streams to a mild stressor and recorded their opercular beat rates. Fish from low-predation areas showed higher maximum, minimum and mean opercular beat frequencies than fish from high-predation regions. The change in opercular beat frequency (scope) was also significantly greater in fish from low- than in fish from high-predation regions. Under normal activity levels, however, low predation fish showed a reduced opercular beat frequency, which may be indicative of reduced activity levels or metabolic rate. Opercular beat frequency was negatively correlated with standard length as one would expect based on higher metabolic rates in smaller fish. We suggest that these contrasting stress responses are most likely the result of differential exposure to predators in fish from high- and low-predation areas. We argue that reduced stress responses in high-predation areas evolved to prevent excessive energy expenditure by modulating the fright response.
\end{abstract}

\section{Introduction}

Variable exposure to predation pressure has dramatic effects on virtually all aspects of an animal's biology, encompassing physiology, behaviour, morphology and life-history traits (Endler 1995). Predators place considerable stress on their prey both physiologically and psychologically (Pfeiffer 1962). Recent studies have revealed that non-lethal costs of predation stem not only from lost foraging opportunities but also from increased energetic expenditure (Fraser and Gilliam 1992). Perhaps the best illustration of this is the fright or flight response (e.g. Barreto et al. 2003). The flight response involves all manner of correlated physiological changes in response to potential danger including rapidly increasing heart and ventilation rates (Metcalfe et al. 1987; Höjesjö et al. 1999). However, the repeated production of a fright response is extremely costly both in terms of time lost from other potential behaviours such as feeding, and in the sheer amount of energy consumed during the mobilisation of glycogen stores. One would expect, therefore, that such responses would be modulated in a manner whereby animals only show these responses in appropriate situations. Vital parameters not only include an animal' $s$ immediate response to stressful situations (i.e. their change in metabolic rate), but also how quickly they recover from them (Cooke et al. 2003). 
In regions where predators are relatively abundant and interactions between predators and prey are common, stress responses resulting from predator disturbance may become attenuated in prey animals through natural selection and, or, through plasticity within the lifetime of an individual. Laboratory experiments in which drosophila were reared in a stressful environment showed higher fitness when exposed to a novel stress than those reared under less-stressful conditions (Reed et al. 2003). At the other end of the scale, rat pups handled for 15 min per day over a couple of weeks had up to $50 \%$ lower glucocorticoid levels in response to moderate stressors than those that had not been handled (Caldjii et al. 2000). Evidently exposure to stresses early on in life and over evolutionary time can induce substantial long-term changes in the hypothalamic-pituitary-adrenal axis in mammals and homologous systems in other taxa (e.g. hypothalamic-pituitary-interrenal in fishes).

Variation in stress response between species is reasonably well documented. For example, six days after being towed in a net for $15 \mathrm{~min}$, juvenile walleye pollock (Theragra chalcogramma Pallas) showed reduced feeding responses followed by $100 \%$ mortality after 14 days. Juvenile sablefish (Anoplopoma fimbria Pallas), by contrast, returned to normal feeding levels after 6 days and fully recovered (Olla et al. 1997). Despite obvious differences at the species level (the comparison above is actually at the order level), variation in stress responses within a species, at the population level, has yet to be described in wild populations (but see changes in physiology associated with temperature gradients-DeKoning et al. 2004). Perhaps the closest comparison is the divergence between captive-reared and wild animals. There have been a number of studies examining differences in stress responses between hatchery-reared and wild salmonids; however, the results to date have been somewhat equivocal (Miller 1954; Pottinger and Carrick 1999; Poole et al. 2003). Johnsson et al. (2001) compared the heart rates of wild and domesticated Atlantic salmon (Salmo salar Linnaeus) when exposed to predation pressure and found that whilst age 1+ wild salmon had higher heart rates in response to a predator than farmed fish, aged 2+ fish had lower heart rates. This result was probably due to the vast difference in escape responses displayed by hatchery and wild fish, with wild age 1+ fish showing significantly longer flight duration. Other factors, such as size differences between strains, can also have substantial effects on stress responses and clearly need to be accounted for (Cooke et al. 2003). Despite the contrasting results documented for captive reared species, it is generally accepted that artificial and natural selection occurs rapidly in captive populations and the process of domestication can lead to differences in the manner in which animals cope with stress (eg. fish: Lepage et al. 2000; mammals: Clutton-Brock 1989; Kunzl and Sachser 1999: birds: Haase and Donham 1980). Such differences are also likely to occur in the wild where geographic variation in ecological pressures, such as predation, may have a substantial effect on the evolution of stress responses.

Heart rate and gill ventilation frequency are strongly affected by body size and water temperature in fishes (Schmidt-Nielson 1997) and are highly correlated with metabolic rate (Grantner and Taborsky 1998). Nevertheless, under standard conditions ventilation frequency is a very sensitive measure of response to disturbance (Lucas et al. 1993; Barreto and Volpato 2004). Moreover, recording ventilation frequency is preferable to other invasive techniques, such as blood sampling, as it minimises experimental stress, thus contributing to improved animal welfare and simplification of experimental design and interpretation (Ellis et al. 2004). In addition, invasive techniques simply cannot be performed on small fishes, and thus, the work to date has tended to focus on large commercial fishes. Yet recording opercular ventilation can provide insights into the metabolic expenses of many activities and can, therefore, provide an important tool for physiologists and behavioural ecologists alike (Grantner and Taborsky 1998; Romero 2004).

Here, we compared the opercular beat frequency (OBF) of a small tropical poeciliid, Brachyraphis episcopi (Steindachner), collected from regions of high- and low-predation pressure in four independent 
streams in the Republic of Panama. Female fish from each of the eight populations were exposed to a mild stressor (confinement) and their ventilation rates were monitored for 20 minutes. In addition, we recorded opercular beat frequencies during normal activity levels in their home tanks. We predicted that fish from high-predation areas would show reduced stress responses compared with fish from lowpredation areas.

\section{Methods}

Female fish were collected from four streams (Quebrada Juan Grand-QJG, Rio Limbo-RL, Rio MachoRM and Rio Agua Salud-AS) that run independently into the Panama Canal. Each of these streams contains a barrier waterfall. Above these falls, only two species exist; the poeciliid Brachyraphis episcopi and killifish Rivulus brunneus (Meek and Hildebrand). Below the falls, a full compliment of the fish fauna is present, including a multitude of predators (see Brown and Braithwaite 2004 for further details of the fauna). The high- and low-predation collection locations within each stream were less than $50 \mathrm{~m}$ apart. This short distance reduced the possibility that any other environmental factors could influence the behaviour of the fish. Fish from these populations differ in a number of attributes including life history parameters (Jennions and Telford 2002), cognitive ability (Brown and Braithwaite 2005) and pattern of cerebral lateralisation (Brown et al. 2004), all of which are attributed to differential exposure to predators. The fish were transported to the University of Edinburgh where they were housed in standard $90 \times 30 \times 30$ $\mathrm{cm}$ aquaria. The benthos was composed of river gravel and filtration was achieved by use of a power filter. The fish were fed once a day using commercial flake food with occasional live food supplements. Lighting was provided by overhead fluorescent tubes maintaining a 12:12 light:dark cycle and room temperature was maintained at $26^{\circ} \mathrm{C}$.

The test apparatus consisted of a small plastic aquarium $(18 \times 23 \times 25 \mathrm{~cm} ; \mathrm{L} \times W \times H)$ into which a plastic "constraint" container $(6 \times 6 \times 15 \mathrm{~cm})$ was placed at one end. Water depth was maintained at $18 \mathrm{~cm}$. The constraint container was transparent and contained holes to permit water flow. A digital video camera was mounted overhead on a tripod to allow recording to take place. The camera was on full zoom and focused entirely on the constraint container, enabling us to observe opercular beats once the test fish was placed inside. The entire set-up was surrounded by opaque material to block out external disturbances.

Four female fish were chosen at random, removed from their housing aquaria, individually placed into clear, numbered, floating tubs in a holding aquarium and allowed to adjust to the new surroundings. After $1 \mathrm{l} / 2 \mathrm{~h}$, the fish were fed and then left for a further $20 \mathrm{~h}$ prior to testing the following day. This procedure was used to minimise any differences in stress levels that may have accumulated due to differential responses to netting the fish out of their home tanks. We allow all fish equal access to food prior to testing as this is known to influence heart rate (Höjesjö et al. 1999). There was no difference in the average standard length ( \pm SE) of the fish used in the study ( 40.8 and $40.6 \pm 0.5 \mathrm{~mm}$ for high- and low-predation fish, respectively; ANOVA: $F_{1,56}=0.062, P=0.804$ ). Nor was there a significant difference between rivers (ANOVA: $F_{3,56}=2.425, P=0.075$ ).

On the morning of testing, one of the four test fish was gently transferred from its floating tub in the holding aquarium into the constraint container within the test aquarium. Video recording continued for a maximum of 20 min during which time the fish was not disturbed. The test fish was then removed and placed back into its floating tub in the holding tank. We noted during previous observations of these fish that some fish showed a peculiar red blushing across the snout, the intensity and location of which seemed to vary between fish. Therefore, we subjectively scored the blushing intensity using an index (0absent, 1-faint, 2-intense) and noted the location of blushing around the head at the end of the observation period. After a brief recovery period, the fish were removed from the holding tank and their standard length and weight were recorded three times and an average for each individual calculated. The 
entire procedure was repeated for the remaining three test fish, after which the test aquarium was rinsed and refilled. A total of 64 fish were tested over 16 days, eight from each of the eight populations.

The recorded video was viewed on a computer screen using Sony DVGate as a time source. This time lapse video analysis allowed the time taken for 20 opercular beats to occur to be noted (after Barreto et al. 2003). This was done for 8 time periods across the total recording time (from 0-1 min, 1-2 min, 2-3 min, 3-4 min, 4-5 min, 9-10 $\mathrm{min}, 14-15 \mathrm{~min}$ and 19-20 $\mathrm{min}$ ). Data were recorded as close to the start of that time period as possible given the movement of the fish. When frightened, the fish tended to freeze; however, movements occurred more frequently towards the end of the recording period, making it difficult to reliably calculate opercular beats and by the 20th minute there were too many gaps in the data-set to allow confident analysis. Therefore, we present data for the first seven observation periods only. The time taken for 20 opercular beats to occur was transformed into beats per minute and analysed using repeated measures ANCOVA with river and predation regime as fixed factors, and standard length as a covariate. The scope of the opercular beat frequency was calculated by subtracting each individual's lowest recorded frequency, over the 15 min confinement period, from the highest recorded frequency. Four individuals had too few readings during the confinement period to make a reliable estimate of scope and were not included in the analysis. The scope data were analysed using ANCOVA with standard length as a covariate, and river and predation regime as fixed effects.

The snout blush index was analysed using nonparametric statistics. In addition, we chose ten fish at random and recorded opercular beat frequency whilst the fish were still in their home tanks. These observations were conducted at various times of the day over many days and the lowest set of opercular beat frequency recorded for any of these observation periods was analysed using ANOVA. In all cases, the data were checked for departures from normality and homogeneity of variance prior to analysis.

\section{Results}

Analysis of OBF of the fish during periods of "normal" activity in their home tanks reveals that highpredation fish had elevated OBF compared with their low-predation counterparts $\left(F_{1,72}=32.335\right.$, $P<0.0001$; Fig. 1). There are also significant differences between each of the streams $\left(F_{3,72}=31.127\right.$, $P<0.0001)$. There was no significant difference in the standard length of the high- and low-predation fish when all of our fish were measured $\left(F_{1,123}=0.479, P=0.49\right)$.

When exposed to a mild stressor, fish from high-predation areas had significantly higher mean OBF than fish from low-predation areas $\left(F_{1,55}=16.293, P=0.002\right.$, Fig. 2$)$ and OBF decreased significantly with time $\left(F_{6,336}=39.326, P<0.001\right)$. OBF also varied significantly between rivers $\left(F_{3,55}=26.282, P<0.001\right)$. The manner in which the OBF changed over time also varied between streams $\left(F_{18,336}=2.905, P<0.0001\right)$. Further, there was a significant three-way interaction between time, river and site $\left(F_{18,336}=2.066\right.$, $P=0.0068$ ). All rivers showed a significant difference in mean OBF over the 15-min interval between fish from high- and low-predation regions with the exception of the Rio Macho. Furthermore, a slightly negative but significant correlation between standard length and mean OBF over the 15 min of confinement was detected $\left(F_{1,62}=4.871, P=0.031\right)$, suggesting that in general smaller fish have higher opercular beat frequencies than larger fish (Fig. 3). Despite differences in the wild, there were no significant differences between the lengths of the fish from the high- and low-predation populations used in this experiment.

The maximum opercular beat frequency recorded during the confinement period for each individual was greater in fish from low-predation regions than those from high-predation regions (193 and $172 \mathrm{bpm}$, respectively; $F_{1,51}=18.779, P<0.001$ ) and this was also true for the minima (144 and $132 \mathrm{bpm}$, respectively; $\left.F_{1,51}=10.304, P=0.002\right)$. The scope of high-predation fish was significantly smaller than 
that of low-predation fish (39.3 and $48.5 \mathrm{bpm}$, respectively; $F_{1,51}=5.233, P=0.026$ ) (Fig. 2). There was no significant interaction between the main effects $\left(F_{3,51}=2.654, P=0.058\right)$. The difference between the maxima and minima opercular beat (scope) also differed significantly between rivers $\left(F_{3,51}=6.367\right.$, $P<0.001)$.

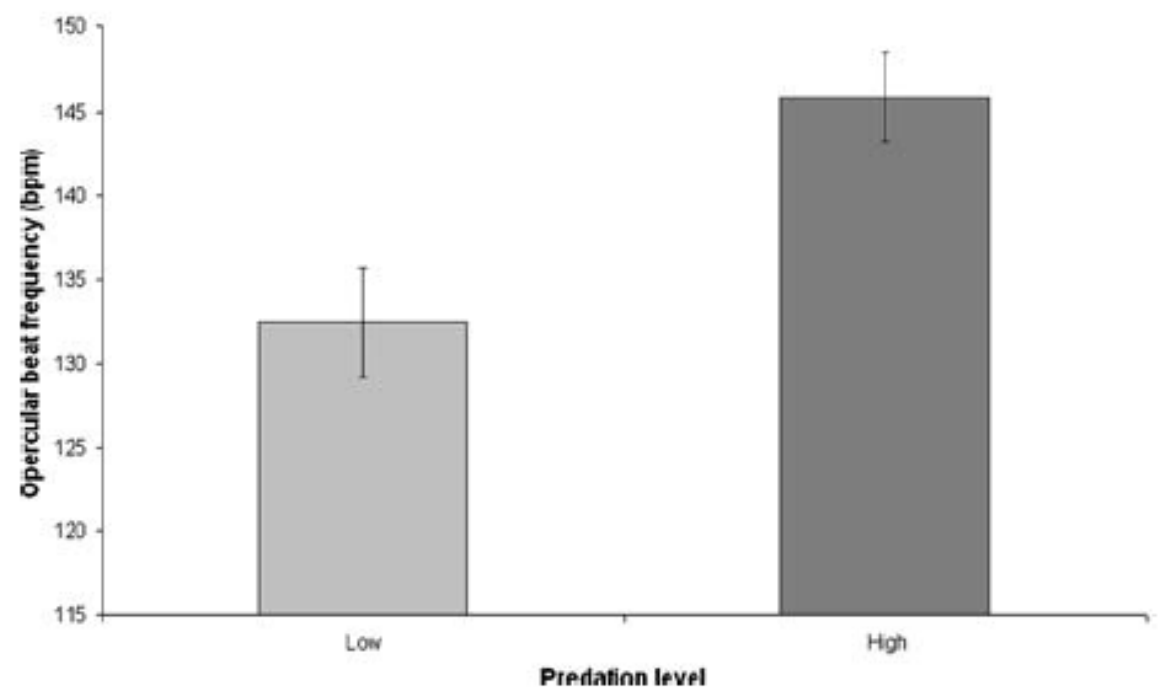

Fig. 1. The mean ( $\pm \mathrm{SE}$ ) opercular beat frequency (beats per minute) of fish from high- and low-predation sites in all four rivers combined under normal activity levels in their home tanks

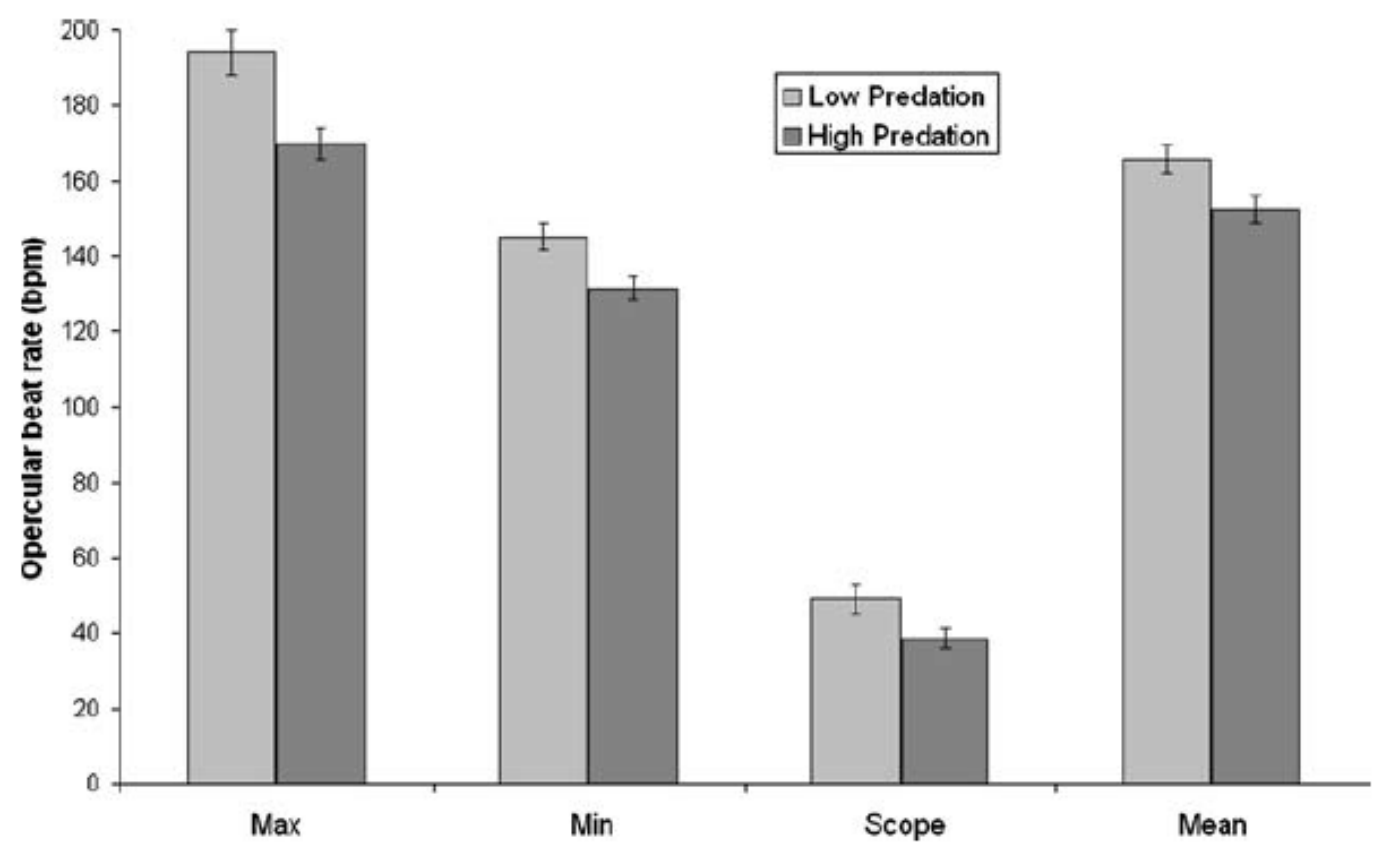

Fig. 2. The maximum, minimum, scope (max-min) and mean number of opercular beats per minute for fish from low-predation and high-predation regions from all four rivers combined when exposed to a mild stressor. Error bars represent standard error 


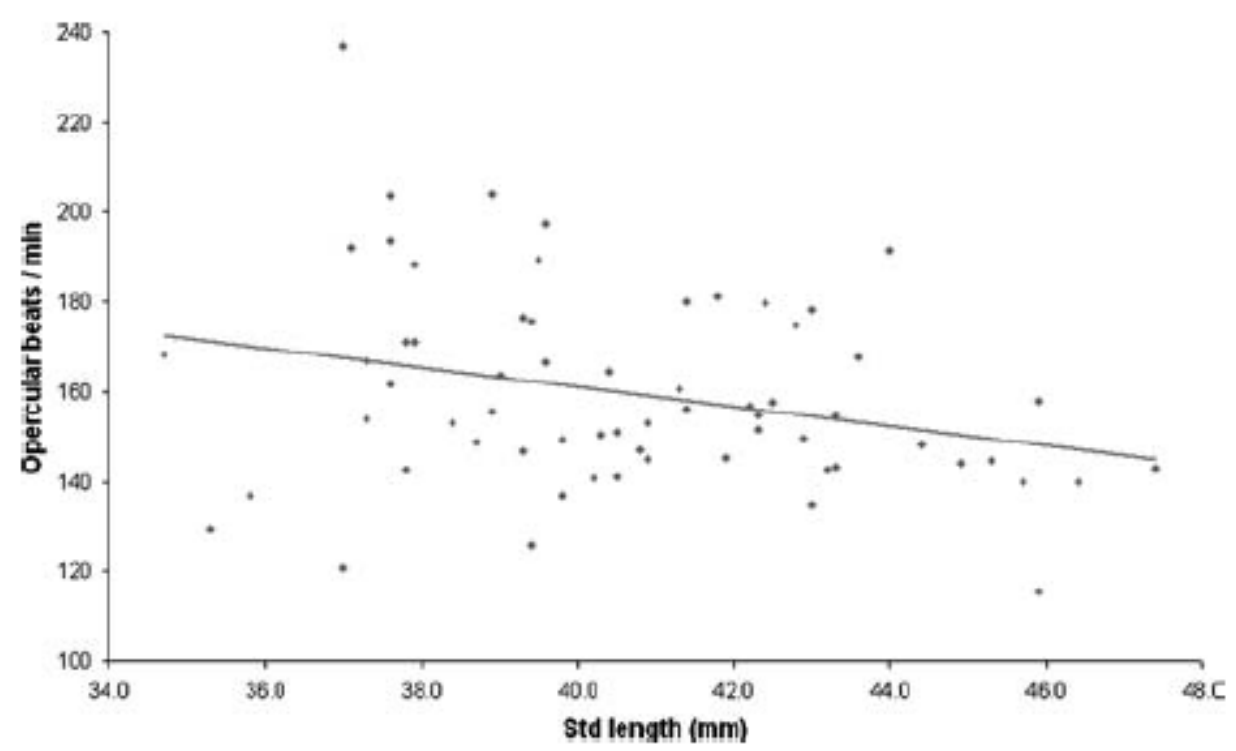

Fig. 3. The relationship between the mean opercular beat frequency during exposure to a mild stressor and standard length. Larger fish tend to have slightly lower opercular beat rate than smaller fish

The analysis of the blush index showed the opposite pattern to that of the OBF data and therefore appears to be inversely correlated with stress response. Whilst there was no significant difference between fish from low- and high-predation regions overall (Mann-Whitney $U$ test: $Z=-1.519, P=0.129$ ), there was a trend for upstream fish to have lower blush indices than downstream fish. There were large differences between rivers (Kruskal Wallace: $H=10.928, P=0.012$ ). The general trend between rivers (i.e. QJG $<A S<R L=R M$ ) was the opposite to that of the OBF data. Fish with high blushing indices tended to be larger than those with lower blushing indices (Kruskal Wallace: $H=11.037, P=0.004$ : Fig. 4.).

It is possible that, within any given batch of four fish tested on any given day, the fish may have been responding to chemical cues emanating from frightened conspecifics tested on the same day. If this is the case, one would expect stress responses to increase with the order in which the fish were tested. However, there was no evidence of an order effect in the OBF data (ANCOVA: $F_{3,56}=0.0471, P=0.70$ ).

\section{Discussion}

Here, we show for the first time that fish from regions of high- and low-predation pressure show differential responses to a mild stressor. Fish from regions of high predation had significantly lower maxima, minima and average opercular beat frequencies (172, 132 and $150 \mathrm{bpm}$, respectively) when exposed to a mild stressor than fish from low predation regions (193, 144 and165 bpm, respectively). Fish from high-predation regions also showed a smaller change (scope) in opercular beat when exposed to stress than fish from low-predation regions. Fright responses are energetically costly for all animals including fishes (Cooke et al. 2003). The reduced responses observed in the fish from high-predation fish suggest that they are less likely to waste energy on fright responses when exposed to mild threatening stimuli and probably reserve their energy for responses to more extreme stresses such as the appearance of predators. In all of the rivers we examined here, B. episcopi makes up only a very small proportion of the fish fauna in the high-predation locations. The overwhelming majority of the fish in these 
areas are the tetras (Charicidae) and a wide range of other potential predators (Brown and Braithwaite 2004). Brachyraphis episcopi in these areas are constantly under threat from predators and there is likely to be heavy selection against individuals that waste energy in frequent or unnecessarily large physiological responses to frightening stimuli. In this manner, fright responses are dampened in fish from high-predation areas. Fish from low-predation areas, in contrast, make up more than $90 \%$ of the fauna and are rarely disturbed by predators; subsequently, any pressure on these populations to modulate their fright or flight reactions is unlikely.

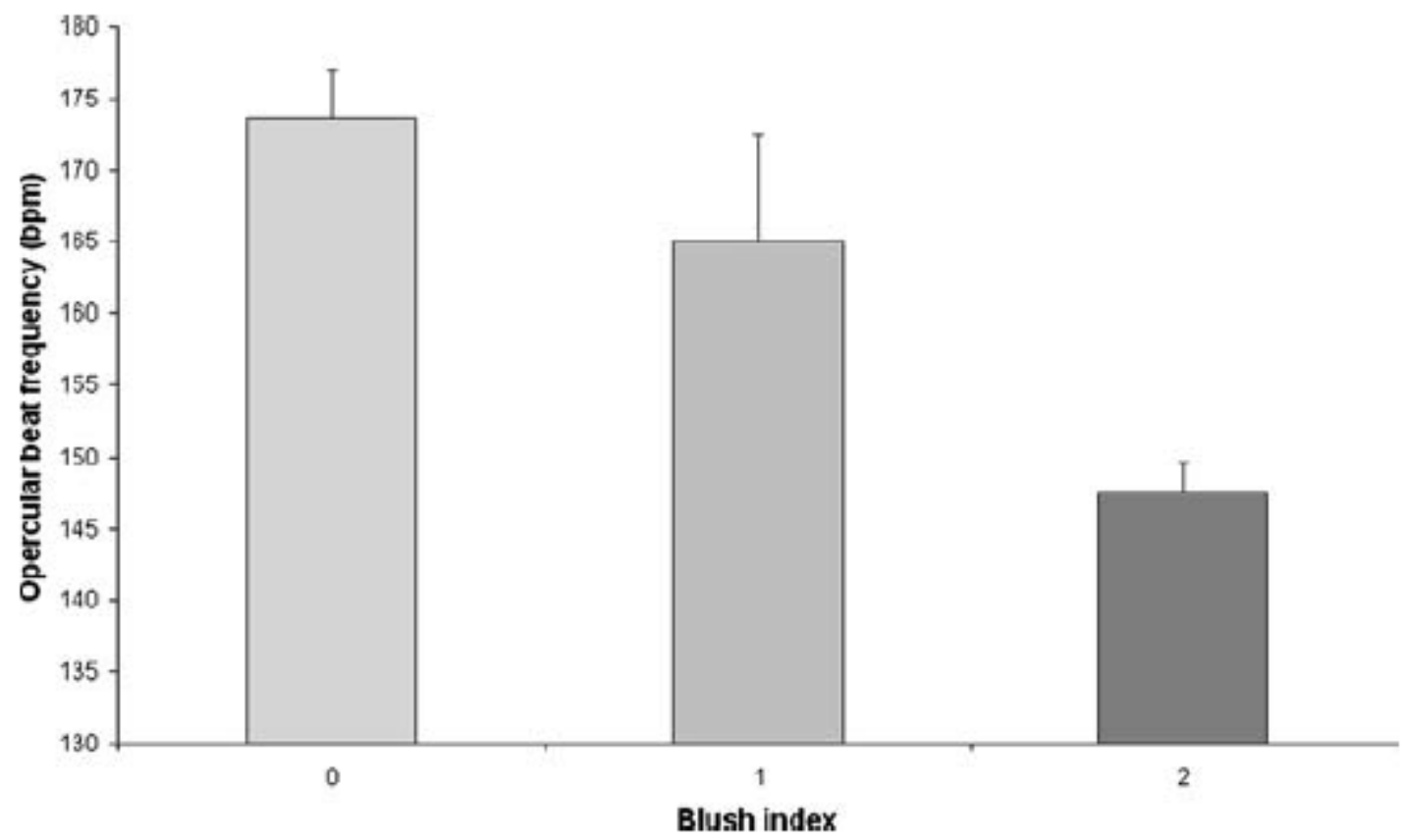

Fig. 4. The relationship between mean ( \pm SE) opercular beat frequency (beats per minute) and snout blush index. A blush index of 2 refers to the highest level of blushing observed in response to a mild stressor

In the present study, fish were captured from very similar environments with the only major difference between them being the in-stream fauna, which limits the possible reasons for the differences in stress responses observed (Brown and Braithwaite 2004; Brown et al. 2005). There were also large differences in responses between the rivers, but this is most likely due to environmental variation at the catchment scale. Furthermore, the fish had been held in captivity for over a year prior to testing. This implies that the differences in stress responses must be either determined early on in development, or have a heritable component. Selective breeding for stress responses in captivity can rapidly result in differentiation between strains of fish (Fevolden et al. 2003; Øverli et al. 2001). Tests are underway to determine the stress responses of laboratory-reared offspring from the same populations as those tested here.

The maximum OBF observed in Brachyraphis episcopi in our experiments (around $190 \mathrm{bpm}$ ) are higher than most reports of fishes under normoxic conditions, but there is a general lack of studies on small fishes for comparison. Robb and Abrahams (2003) report that fathead minnows Pimephales promelas (Rafinesque) in normoxic conditions had ventilation rates of about $180 \mathrm{bpm}$. The African rift lake cichlid Neolamprologus pulcher (Trewavas and Poll) can have OBFs during high levels of activity of up to126 bpm (Grantner and Taborsky 1998). Similar rates (i.e. ca. 120 bpm) are reported for several species at 
high swimming velocity (e.g. whiting, Gadus merlangus Linnaeus-Hughes 1960; brown trout, Salmo trutta Linnaeus, pumpkinseeds, Lepomis gibbosus Linnaeus and bullheads Ictalurus nebulosus LesueurSutterlaind 1969). All of these species are substantially larger than B. episcopi and given that larger fish have a lower metabolic rate (Clarke and Johnston 1999) it is difficult to make any sensible comparisons. One must bear in mind that in the present study the water was well oxygenated and the fish could hardly move during the confinement period. The conditions of testing (i.e. in confinement) correspond quite well with the fright reaction of most individuals in this species, which is to freeze rather than school in response to threat (Brown, unpublished data). Indeed, activity levels tended to increase towards the end of the confinement period as the fish recovered and OBF decreased accordingly. The response during the confinement period, therefore, is entirely due to stress rather than changes in activity levels. Similar observations have been made in a wide range of animals including red deer calves where freezing in response to frightening stimuli is likewise associated with changes in breathing and heart rate (Espmark and Langvatn 1985).

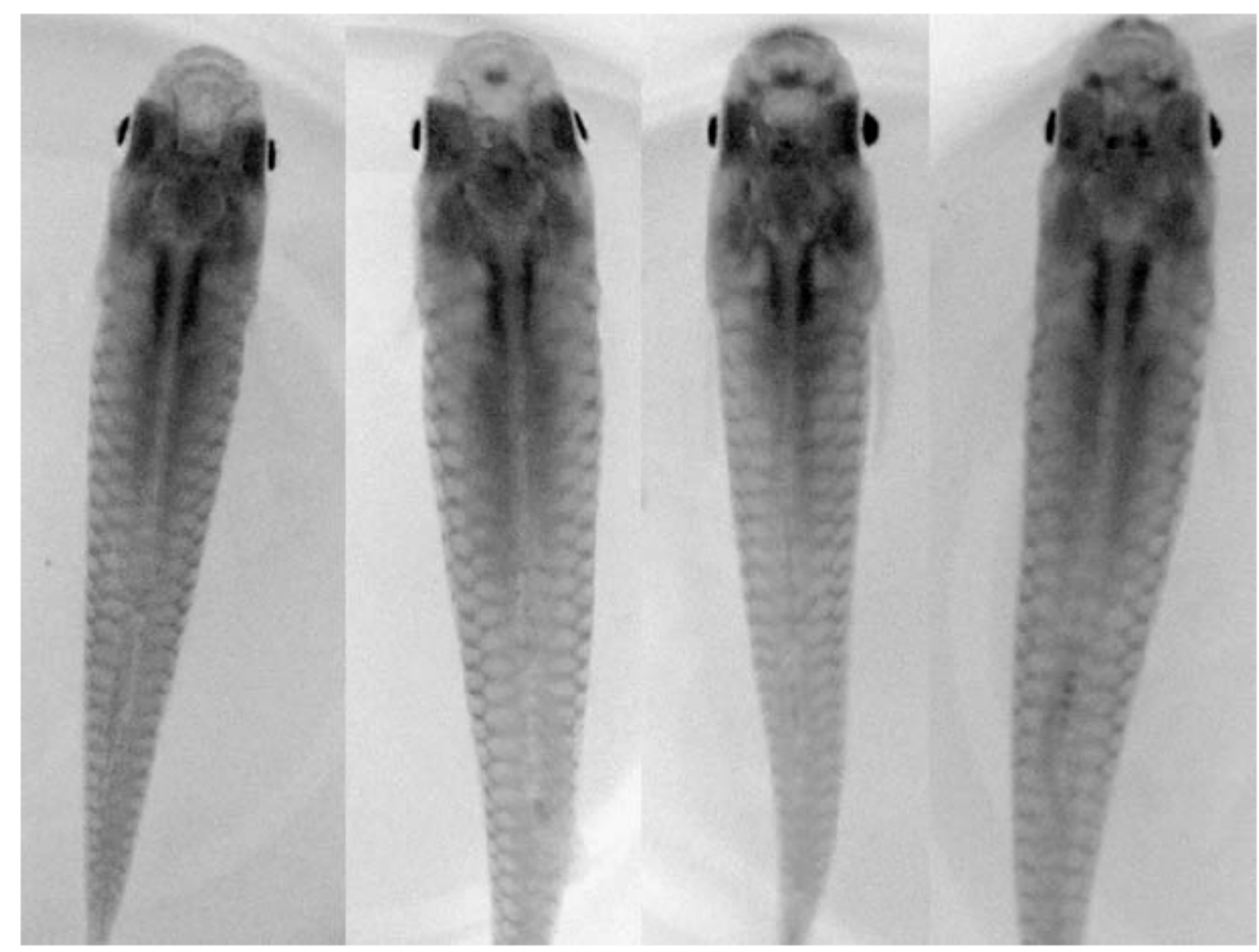

Fig. 5. Fish displaying varying degrees of blushing in the snout in response to a mild stressor ranging from no blushing on the left to intense blushing on the right. Note also that the pattern of blushing in the two fish on the right differs

In the present study, fish from both regions gradually calmed down as indicated by a decline in opercular beat frequency by the 15th minute of confinement. In some cases (particularly in fishes from high- 
predation sites), ventilation rates by the end of the confinement period were lower than those under normal activity levels probably because the confined conditions preventing the fish from normal activity. No difference in recovery rate was evident between fish from high- and low-predation locations, suggesting that the entire response has been shifted down in fish from high-predation regions. These results are consistent with the notion that repeated exposures to stress in the wild leads to an attenuated stress response over evolutionary and/or ontogenetic time frames (as with rats; Caldji et al. 2000).

Interestingly, fish from high-predation areas had higher ventilation rates under normal activity levels than fish from low-predation regions, which implies that they may have higher general activity levels or underlying metabolic rates. Informal observations of the fish in their home tanks, however, suggest that there are no obvious differences in activity. Nevertheless, increased activity levels, general alertness and associated higher ventilation rates might be beneficial in areas of high-predation areas since the fish could respond to threat more readily. Whilst fish significantly alter their OBF in response to a mild stress in this study, this is only a part of the full physiological response. Fish also alter the ventilation volume by increasing opercular amplitude (Schmidt-Nielson 1997). The differences in response reported here, therefore, are probably a conservative estimate of the true physiological differences between fish from high- and low-predation regions. A more direct measure of metabolic rate may be gained by placing the fish in respirometers (Fig. 5).

We also found a significant relationship between standard length and OBF. Increased metabolic rate results in increased ventilation frequency (Claireaux and Lagardere 1999), which in turn, is inversely proportional to body size (Jones 1971; Schmidt-Nielsen 1997). There are differences in the mean body size of fish from high- and low-predation pressure in the wild (low-predation fish tend to be larger; Jennions and Telford, 2002; Brown et al., 2005), which could potentially explain upstream and downstream differences in ventilation frequency. However, there was no difference in the size of the fish used in this experiment. The fact that differences in standard length between fish from high- and lowpredation regions have been extirpated after prolonged periods in captivity suggests that removal from the natural environment also removes the constraints forcing fish to follow alternate life-history strategies (Jennions and Telford 2002). This observation warrants further investigation.

Despite the fact that the level of predation experienced in the wild is the most likely explanation for the differences in stress responses in our system, there may be alternatives. One possibility is that the fish living in downstream areas occupy regions closer to the limit of their distribution. The range of this species is restricted to upland streams and Brachyraphis episcopi is replaced by a more fusiform sister species Brachyraphis cascayalensis (Meek and Hildebrand) as one moves downstream towards the Panama Canal. Sequence data suggest that the two species are not closely related and are representative of an ancient split between Pacific and Atlantic clades (Majica 1998). In many rivers in the region, the transfer from one species to the other is abrupt, whilst in others the species coexist for small stretches of the river. Dunlap and Wingfield (1995) found that lizards living close to the periphery of the species distribution tended to have elevated basal levels of glucocorticoids than those living in the core of the distribution presumably owing to reduced habitat quality. This pattern is similar to that observed in $B$. episcopi with downstream fish having elevated opercular beat frequencies under normal levels of activity, but it does not correspond to data collected during the confinement period. In addition, in all of the sites we tested herein the distribution of $B$. episcopi continues for over a kilometre in either direction of our collection sites, so this is an unlikely explanation for the observed results. Differences in stress responses have also been observed in populations of Fundulus hetericlitus (Linaeus) in response to temperature clines (DeKoning et al. 2004). One must bear in mind, however, that because we deliberately collected fish in locations above and below waterfalls that were very close to one another, there is very little difference in the physical properties of the two habitats in any of the rivers (e.g. mean \pm SE annual water 
temperature for the Rio Macho high-predation and low-predation sites for August 2002-July 2003 was $24.6 \pm 0.050$ and $24.6 \pm 0.047$, respectively).

Another potential, alternative explanation to that provided above is that fish from high-predation areas may not be able to increase their ventilation rate to the same extent as those from low-predation areas when exposed to a stressful situation because adaptations to sustain higher metabolic rates can reduce the potential to respond to stressors (Øverli et al. 1999; Barcellos et al. 1999; Basu et al. 2001; Haukenes and Barton 2004). However, this argument seems unlikely and assumes that all populations have similar OBF maxima. The maximum OBF observed here probably do not reflect the absolute maximum the fish can achieve since the stress applied to them was only of a very mild form. Indeed, we argue that the highpredation fish probably reserve large-scale physiological responses for only very stressful situations such as pursuit by predators. Further research will reveal if this is indeed the case.

Our index of the blushing response seen in the snout of the fish was negatively correlated with OBF and positively correlated with standard length. The exact nature of the blushing response in these fish remains unknown; however, there are a number of possible explanations. Firstly, it may be that these fish cease ventilation as part of a general reliance on crypsis in response to predation threat. By reducing ventilation, there may be a build up of metabolites in the blood leading to vaso-dilation and the blood may be sequestered to low-pressure, surface vessels. It may be that this response can only be maintained in larger individuals with lower basal metabolic rates. Notice, however, that in this case the blushing is confined to the snout. There is no evidence of blood moving to the surface anywhere else in the body (Fig. 6). Perhaps the most likely explanation for this observation is an increase in blood flow to the nasal region associated with an increased chemosensory capacity. Such a response may result in increased awareness of approaching predators, but its negative association with standard length and OBF is difficult to explain.

In conclusion, it is evident that fish from high- and low-predation regions differ substantially in their responses to a mild stressor. Fish from high-predation areas show lower maximum, minimum, mean and scope than fish from low-predation areas. This difference is most likely the results of repeated exposure to predators in downstream areas, resulting in selection for attenuated stress responses as observed in other taxa. The extent to which this differentiation occurs over evolutionary time and/or during ontogeny remains to be explored. Opercular beat frequency was also negatively correlated with standard length as one would expect based on the relationship between standard length and metabolic rate. That the observed blushing in the snout of the fish was negatively correlated with opercular beat rate and positively correlated with standard length indicates that this response is most likely to be linked in some way $\mathrm{t}$

o the stress response but it may also serve to increase chemosensory sensitivity.

\section{Acknowledgements}

We thank the Smithsonian Tropical Research Institute for their continued support and Fiona Burgess for her aid with husbandry. Thanks also to Felicity Brown for her help collecting the fish. The fish were collected and exported under licence from the Panamanian authorities (ANAM permit\# 31503). This work was funded by NERC grant no NER/A/S/01/00608. 


\section{References}

Barcellos LJG, Nicolaiewsky S, de Souza SMG, Lulhier F (1999) Plasmatic levels of cortisol in the response to acute stress in Nile tilapia, Oreochromis niloticus (L), previously exposed to chronic stress. Aquacult Res 30:437-444

Barreto RE, Volpato GL (2004) Caution for using ventilator frequency as an indicator of stress in fish. Behav Processes 66:43-51

Barreto RE, Luchiari AC, Macondes AL (2003) Ventilatory frequency indicates visual recognition of an allopatric predator in naïve Nile tilapia. Behav Processes 60:235-239

Basu N, Nakano T, Grau EG, Iwama GK (2001) The effects of cortisol on heat shock protein 70 levels in two fish species. Gen Comp Endocrinol 124:97-105

Brown C, Braithwaite VA (2004) Size matters: a test of boldness in eight populations of the poeciliid, Brachyraphis episcope. Anim Behav 68:1325-1329

Brown C, Braithwaite VA (2005) Effects of predation pressure on the cognitive ability of the poeciliid Brachyraphis episcopi. Behav Ecol 16:482-487. doi:10.1093/beheco/ari016

Brown C, Gardner C, Braithwaite VA (2004) Population variation in lateralised eye use in the poeciliid Brachyraphis episcopi. Proc R Soc Lond Ser B (Suppl) 271:S455-S457

Brown C, Jones FC, Braithwaite VA (2005) Environmental influences on boldness-shyness traits in the tropical poeciliid, Brachyraphis episcopi. Anim Behav (in press)

Caldji C, Francis D, Sharma S, Plotsky PM, Meaney MJ (2000) The effects of early rearing environment on the development of GABAA and central benzodiazepine receptor levels and novelty-induced fearfulness in the rat. Neuropsychopharmacology 22:219-229

Claireaux G, Lagarde're JP (1999) Influence of temperature, oxygen and salinity on the metabolism of European sea bass. J Sea Res 42:157-168

Clarke A, Johnston NM (1999) Scaling of metabolic rate with body mass and temperature in teleost fish. J Anim Ecol 68:893-905. doi:10.1046/j.1365-2656.1999.00337.x

Clutton-Brock T (1989) A natural history of domesticated mammals. Cambridge University Press, Cambridge

Cooke SJ, Steinmetz J, Degner JF, Grant EC, Philipp DP (2003) Metabolic fright responses of differentsized largemouth bass (Micropterus salmoides) to two avian predators show variations in nonlethal energetic costs. Can J Zool 81:699-709

DeKoning ABL, Picard DJ, Bond SR, Schulte PM (2004) Stress and interpopulation variation in glycolytic enzyme activity and expression in a teleost fish Fundulus heteroclitus. Physiol Biochem Zool 77:18-26

Dunlap KD, Wingfield JC (1995) External and internal influences on indexes of physiological stress 1 Seasonal and population variation in adrenocortical secretion of free-living lizards, Sceloporus occidentalis. J Exp Zool 271:36-46

Ellis T, James JD, Stewart C, Scott AP (2004) A non-invasive stress assay based upon measurement of free cortisol released into the water by rainbow trout. J Fish Biol 65:1233-1252

Endler JA (1995) Multiple-trait coevolution and environmental gradients in guppies. Trends Ecol Evol 10:22-29

Espmark Y, Langvatn R (1985) Development and habituation of cardiac and behavioral-responses in young red deer calves (Cervus elaphus) exposed to alarm stimuli. J Mammal 66:702-711

Fevolden SE, Roed KH, Fjalestad K (2003) A combined salt and confinement stress enhances mortality in rainbow trout (Oncorhynchus mykiss) selected for high stress responsiveness. Aquaculture 216:67-76 
Fraser DF, Gilliam JF (1992) Nonlethal impacts of predator invasion-Facultative suppression of growth and reproduction. Ecology 73: 959-970

Grantner A, Taborsky M (1998) The metabolic rates associated with resting, and with the performance of agonistic, submissive and digging behaviours in the cichlid fish Neolamprologus pulcher (Pisces: Cichlidae). J Comp Physiol B 168:427-433

Haase E, Donham RS (1980) Hormones and domestication. In: Epple A (ed) Avian Endocrinology. Academic, Santiago, pp 549-561

Haukenes AH, Barton BA (2004) Characterization of the cortisol response following an acute challenge with lipopolysaccharide in yellow perch and the influence of rearing density. J Fish Biol 64:851862

Höjesjö J, Johnsson Jl, Axelsson M (1999) Behavioural and heart rate responses to food limitation and predation risk: an experimental study on rainbow trout. J Fish Biol 55:1009-1019

Hughes GM (1960) A comparative study of gill ventilation in marine teleosts. J Exp Biol 37:28-45

Jennions MD, Telford SR (2002) Life-history phenotypes in populations of Brachyrhaphis episcopi (Poeciliidae) with different predator communities. Oecologia 132:44-50

Johnsson JI, Höjesjö J, Fleming IA (2001) Behavioural and heart rate responses to predation risk in wild and domesticated Atlantic salmon. Can J Fish Aquat Sci 58:788-794

Jones DR (1971) Theoretical analysis of factors which may limit the maximum oxygen uptake of fish: The oxygen cost of the cardiac and branchial pumps. J Theor Biol 32:341-349

Kunzl C, Sachser N (1999) The behavioural endocrinology of domestication: a comparison between the domestic Guinea pig (Gavia opera $f$ porcellus) and its wild ancestor, the Cavy (Cavia apera). Horm Behav 35:28-37

Lepage O, Øverli O, Petersson E, Jarvi T, Winberg S (2000) Differential stress coping in wild and domesticated sea trout. Brain Behav Evol 56:259-268

Lucas MC, Johnstone ADF, Priede IG (1993) Use of physiological telemetry as a method of estimating metabolism of fish in the natural environment. Trans Am Fish Soc 122:822-833

Majica CL (1998) Comparative ecology and historical biogeography of the genus Brachyraphis. Environ Biol Fishes 51:117-127

Metcalfe NB, Huntingford FA, Thorpe JE (1987) The influence of predation risk on the feeding motivation and foraging strategy of juvenile Atlantic salmon. Anim Behav 35:901-911

Miller RB (1954) Comparative survival of wild and hatchery-reared cutthroat trout in a stream. Trans Am Fish Soc 83:120-130

Olla BL, Davis MW, Schreck CB (1997) Effects of simulated trawling on sablefish and walleye pollock: The role of light intensity, net velocity and towing duration. J Fish Biol 50:1181- 1194

Øverli O, Olsen RE, Lovik F, Ringo E (1999) Dominance hierarchies in Arctic charr, Salvelinus alpinus L: differential cortisol profiles of dominant and subordinate individuals after handling stress. Aquacult Res 30:259-264

$\varnothing v e r l i ~ O$, Pottinger TG, Carrick TR, Øverli E, Winberg S (2001) Brain monoaminergic activity in rainbow trout selected for high and low stress responsiveness. Brain Behav Evol 57:214-224

Pfeiffer W (1962) The fright reaction of fish. Biol Rev 37:495-511

Poole WR, Nolan DT, Wevers T, Dillane M, Cotter D, Tully O (2003) An ecophysiological comparison of wild and hatchery-raised Atlantic salmon (Salmo salar L) smolts from the Burrishoole system, western Ireland. Aquaculture 222:301-314

Pottinger TG, Carrick TR (1999) Modification of the plasma cortisol response to stress in rainbow trout by selective breeding. Gen Comp Endocrinol 116:122-132 
Reed DH, Lowe EH, Briscoe DA, Frankham R (2003) Fitness and adaptation in a novel environment: Effect of inbreeding, prior environment, and lineage. Evolution 57:1822-1828

Robb T, Abrahams MV (2003) Variation in tolerance to hypoxia in a predator and prey species: an ecological advantage of being small?. J Fish Biol 62:1067-1081

Romero LM (2004) Physiological stress in ecology: Lessons from biomedical research. Trends Ecol Evol 19:249-255

Schmidt-Nielsen K (1997) Animal physiology: adaptation and environment. Cambridge University Press, Cambridge

Sutterland AM (1969) Effects of exercise on cardiac and ventilation frequency in three species of freshwater teleosts. Physiol Zool 42:36-52 